\title{
Prevalence and associated characteristics of anti- SARS-CoV-2 antibodies in Mexico 5 months after pandemic arrival
}

\section{Cristina Díaz-Salazar}

Municipal Health Clinic of Guadalupe

\section{Adriana Sánchez-García}

Universidad Autónoma de Nuevo León https://orcid.org/0000-0002-6297-7429

René Rodríguez-Gutiérrez

Universidad Autónoma de Nuevo León

Adrián Camacho-Ortiz

Universidad Autónoma de Nuevo León

Donato Saldívar-Rodríguez

Universidad Autónoma de Nuevo León

José Gerardo González-González ( $\nabla$ jgerardo@meduanl.com )

Universidad Autónoma de Nuevo León https://orcid.org/0000-0002-6609-9483

\section{Research Article}

Keywords: COVID-19, prevalence, serology, anti-SARS-CoV-2

Posted Date: October 2nd, 2020

DOl: https://doi.org/10.21203/rs.3.rs-84890/v1

License: (9) This work is licensed under a Creative Commons Attribution 4.0 International License.

Read Full License

Version of Record: A version of this preprint was published at BMC Infectious Diseases on August 19th, 2021. See the published version at https://doi.org/10.1186/s12879-021-06550-5. 


\section{Abstract}

Background: Seroprevalence of anti-SARS-CoV-2 antibodies is now available in several world regions to better estimate transmission dynamics. However, to date, there is no epidemiological data regarding antiSARS-CoV-2 prevalence in Mexico. Therefore, we aimed to determine the prevalence of anti-SARS-CoV-2 antibodies and define the clinical and demographic characteristics associated with seroprevalence in a institutionalized population.

Methods: We conducted a serological survey in Ciudad Guadalupe, NL, Mexico. Institutionalized employees voluntarily participated during July 2020. Demographic and clinical characteristics were collected at the time of blood sampling to analyze the associated characteristics. IgM/lgG antibodies were determined using a qualitative chemiluminescent immunoassay. We reported the raw and the adjusted seroprevalence for test performance characteristics. Descriptive statistics were used for categorical and continuous variables. Statistical significance was tested using the Chi-squared test, Student's t-test and the Mann-Whitney. Logistic regression models and the odds ratios (adjusted and unadjusted) were used to estimate the association of demographic and clinical characteristics.

Results: Of the 3,268 participants included, 193 (5.9\%, 95\% Cl 5.1-6.8) tested positive for lgM/lgG against SARS-CoV-2. Adjusted prevalence by the immunoassay diagnostic performance resulted in a prevalence of 5.7 (95\% $\mathrm{Cl} 4.9-6.6)$. Gender, city of residence, and comorbidities did not show any association with having IgM/IgG antibodies. A total of 114 out of 193 (59.1\%) subjects with a positive test were asymptomatic, and the odds of being positive were higher in those who reported symptoms of COVID-19 in the previous four weeks to the survey (OR 4.1, 95\% $\mathrm{Cl}$ 2.9-5.5).

Conclusions: There is a low rate of SARS-CoV-2 infection among institutionalized employees that have continuously been working during the pandemic. Six in ten infections were asymptomatic, and seroprevalence is low and still far from herd immunity. Epidemiological surveillance and preventive measures should be mandatory.

\section{Background}

Since the first case reported of the SARS-CoV-2 virus was reported in Mexico (February 27, 2020) to date (August 30th, 2020), there are 595,841 confirmed cases and 64,158 deaths [1]. Nuevo Leon, a northern state comprising a population of 5,119,504 inhabitants and which includes one out of the three most populated metropolitan areas in Mexico, has registered 49,457 confirmed cases and 2,403 deaths (August 30th, 2020), placing it in the third position nationwide [2]. Despite the increasing epidemiological surveillance efforts using the gold-standard quantitative polymerase chain reaction (PCR), testing is limited to symptomatic individuals, and it varies widely according to the test availability, even in the same country. Moreover, the occurrence of mild or asymptomatic infections leads to an underestimation of cases. Thus, seroepidemiological studies will allow better estimates of transmission dynamics, cumulative prevalence, and the proportion of the remaining susceptible populations [3]. 
Seroprevalence of anti-SARS-CoV-2 antibodies is now available in several world regions. In Europe, firstly affected by SARS-CoV-2, Germany, Spain, and Switzerland determined a 1.22\% (March-May 2020), 4.6\% (May 2020), and 4.8\% (April-May 2020) antibody prevalence, respectively [4-6]. In the Americas, a 2.8\% seroprevalence was reported in the state of California, United States, during April 2020, while $0.22 \%$ was observed in Brazil during May 2020 in a population-based survey $[7,8]$. However, these serological surveys have been conducted at different epidemic phases in each country, using several immunological assays, sample sizes, and study designs in selected populations (population-based, blood donors, health-care workers) $[5,9,10]$. Thus, information derived from other regions is not a true reflection of the local epidemic's occurrence and transmission. To date, there is no epidemiological data regarding anti-SARSCoV-2 prevalence in Mexico.

We conducted a serological survey in an institutionalized population for the qualitative detection of $\lg M$ and $\lg G$ antibodies against SARS-CoV-2. We aimed to determine, as a primary endpoint, the prevalence of anti-SARS-CoV-2 antibodies and as a secondary endpoint, we defined the clinical and demographic characteristics associated with seroprevalence in the studied population. These results are now implemented for pandemic management in our regional context.

\section{Participants And Methods}

\section{Study design and participants}

We conducted a community level serological survey in Ciudad Guadalupe, the second most populated city (682,880 inhabitants) included in the metropolitan area of Monterrey, Nuevo Leon, Mexico [11]. The participants were drawn from a complete database of 4,220 government employees who were voluntarily invited to participate in this serological survey. Participants were included from July 9 to July 23, 2020. The work was carried out in accordance with Declaration of Helsinki for studies involving humans. Written informed consent was obtained from all participants, according to the research protocol approved by the Institutional Review Board of the School of Medicine and “Dr. Jose E. Gonzalez" University Hospital. Fieldwork was carried out by trained health care professionals in the community health clinic. We obtained demographic (age, gender, zip code, hometown, occupation) and clinical information using a standardized electronic questionnaire focused on symptoms related to coronavirus disease 19 (COVID19), contact with confirmed cases, and comorbidities. After a 4 hour fasting period, blood samples were collected, labeled, and sent to the Metabolic Research Laboratory at the Endocrinology Division of the "Dr. Jose Eleuterio Gonzalez" University Hospital.

\section{Detection of anti-SARS-CoV-2 antibodies}

We selected a qualitative chemiluminescent immunoassay to detect lgM/lgG against SARS-CoV-2 (Elecsys Anti-SARS-CoV-2, Roche, Germany, Ref. 09203079190) using the Cobas e801 automated analyzer (Roche, Germany). The National Health Department approved this test for the diagnostic intended use. The manufacturer reported a $99.5 \%$ sensitivity and specificity of $99.8 \%$ after 14 days postPCR confirmation. This test uses a recombinant protein representing the nucleocapsid $(\mathrm{N})$ antigen for the 
determination of antibodies against SARS-CoV-2 in the serum sample. The software automatically determines chemiluminescent emission by comparing the electrochemiluminescence signal obtained from the sample's reaction product with the signal of the cut-off value previously obtained by calibration (COI, cut-off index) using the positive and negative quality controls.

\section{Statistical analysis}

Statistical analysis was performed in the IBM SPSS Statistic software V22 (IBM Corp., USA) and EpiR for the Statistical Analysis of Epidemiology package [12]. The sample size calculated considering a SARSCoV-2 seroprevalence of $5 \%$, with a precision of $\pm 2.0 \%$ at the $95 \%$ confidence intervals, was 608 subjects. We reported the raw frequencies of positive tests as a proportion of the sample size and the adjusted seroprevalence for test performance characteristics. We compared our estimated cumulative prevalence against the official government PCR-based data of confirmed cases at the time of the survey. Descriptive statistics were used for categorical (frequencies and percentages) and continuous (means and standard deviations) variables. Statistical significance $(P$-value $<0.05)$ was tested using the Chi-squared test for categorical variables, while Student's t-test and the Mann-Whitney test were performed for continuous variables. Logistic regression models and the odds ratios (adjusted and unadjusted) were used to estimate the association of demographic and clinical characteristics identified as statistically significant in the bivariate analysis.

\section{Results}

\section{Overall study population}

A total of 4,220 subjects were invited to participate in the serological survey, including 694 retired employees. During the 11 days of fieldwork, we collected 3,268 (77.4\%) blood samples and clinical data and $952(22.6 \%)$ subjects did not attend the invitation due to planned vacations, sick leave, and work schedule unavailability. Table 1 (at the end of the text) shows the demographic and clinical data. The median age was 40 years (IQR 3-49), and $61.4 \%$ were males. Median BMI was $28.4 \mathrm{~kg} / \mathrm{m}^{2}$, and obesity and overweight were observed in $38 \%$ and $39.4 \%$ of the population, respectively. Previously known hypertension and type 2 diabetes were referred by $8.8 \%$ of participants for both diseases. Besides, $60.3 \%$ declared to live in Ciudad Guadalupe, and police, firefighters, public security, and administrative tasks were the main occupations registered.

\section{Prevalence of anti-SARS-CoV-2 and characteristics of seropositive subjects}

We were able to identify anti-SARS-CoV-2 antibodies in 193 out of 3,268 subjects, resulting in a raw prevalence of $5.9 \%$ (95\% Cl 5.1- 6.7) during July 2020. As shown in Table 2 (near here), when adjusted by sensitivity $(100 \%, 95 \% \mathrm{Cl} 88.1-100)$ and specificity $(99.80 \%, 95 \% \mathrm{Cl} 99.7-99.9)$ reported by the manufacturer's assay at $>14$ days post-PCR confirmation, seroprevalence was $5.7 \%(95 \% \mathrm{Cl} 4.9-6.6)$. 
Cases with positive IgM/lgG were not different in age, gender, weight, height, or BMI from seronegative subjects. There was a statistical difference in the occupation category of cleaning/maintenance ( $P=$ 0.001). At the time of the survey, $83.9 \%$ of the participants had not experienced COVID-19 symptoms, while $33.7 \%$ of the subjects reported a known contact with a confirmed COVID-19 case. As expected, selfreported symptoms during the previous four weeks to the survey were statistically different between the groups (Table 3 , near here), including the contact with a confirmed COVID-19 case ( $P=0.013)$.

\section{Characteristics associated with anti-SARS-CoV-2 seroprevalence}

Gender, city of residence, and comorbidities did not show any association with having $\operatorname{lgM} / \lg$ antibodies against SARS-CoV-2 (Table 4, at the end of the text file); while $59.1 \%$ (114 out of 193) individuals with a positive test were asymptomatic. The odds of being positive were higher in those who reported COVID-19 symptoms in four weeks before the survey (OR 4.06, 95\% Cl 2.99-5.51). Anosmia was the most strongly associated symptom with seropositivity (OR 12.62, 95\% Cl 8.22-19.37), while sore throat was the least (OR $2.93,95 \% \mathrm{Cl} 1.96-4.38$ ). Inversely, being asymptomatic resulted in a $75 \%$ less probability of having a positive IgM/lgG test. Multivariable logistic regression analysis revealed that the odds of being positive were higher in those patients with previous symptoms such as cough, anosmia, and fever (Figure 1). The initial protective effect for the occupation of cleaning/maintenance was no longer observed when adjusted in the multivariate model (OR $0.71,95 \% \mathrm{Cl} 0.46-1.10, P=0.13$ ). Police, firefighters, and public security did not show any association in the univariate or multivariate models.

\section{Discussion}

Our findings from this regional seroprevalence study for SARS-CoV-2 indicate that the prevalence of $\mathrm{IgM} / \mathrm{IgG}$ antibodies against the novel coronavirus is $5.7 \%$ in a city of the metropolitan area of Monterrey. This study is the first data available, since the first case registered in February 2020, on the prevalence of anti-SARS-CoV-2 antibodies in our country. Because our survey was designed to obtain information at a local level, regional differences in cultural habits and other factors might be observed against other areas in Mexico. As the third most populated state in the country, Monterrey's metropolitan area was considered a hotspot for epidemic transmission, and our findings may provide additional data to complete epidemiological surveillance.

Several studies have been published since April 2020 regarding the prevalence of anti-SARS-CoV-2 antibodies. Each one provided a snapshot that mirrors time and space-specific circumstances in the different studied populations and the associated characteristics. Our prevalence was higher than those reported in California, United States (April 2020), and Spain and Switzerland during last May 2020 [5,6], but lower than the $7.3 \%$ determined in the 1,104 samples from the general population of Stockholm, Sweden at the end of April, three months after the pandemic arrival [13]. Previous data for other regions or states in Mexico are not currently available. Given the asynchrony in COVID-19 transmission in our country, different seroprevalences might be found. Serosurveys are a useful tool to determine the previous exposure to SARS-CoV-2 and better estimate the true number of infections with and without 
symptoms. Particularly, Mexico has very limited PCR testing based on the sentinel epidemiological model used for epidemiological surveillance. This survey included a large sample, allowing determining an initial reference of previous exposure in asymptomatic individuals. Furthermore, sampling was made in an institutionalized population that belongs to the exposed essential government workforce. These characteristics will make it feasible for prospective and follow-up studies. In conjunction, the adjusted prevalence of $5.7 \%$, implying that around 39,197 people were infected in Ciudad Guadalupe (population 682,880 in 2015) during July 2020 [11], 11.96 times the average 3,276 PCR confirmed cases (July 9-23) at the time of this survey [2]. Notably, Nuevo Leon has the higher rate of PCR test per million people in our country. Similar assumptions could be made for other regions as soon as local data become available.

In agreement with our findings, gender was not associated with anti-SARS-CoV-2 antibodies either in selected populations, health-care workers, and population-based studies. In contrast, age was associated with higher odds of having a positive test in Brazilian blood donors [14], while the opposite was seen in Swiss children and adults $>65$ years in a population-based survey [6]. Consistently with our results, no association was observed in the professional category, previous contact with a COVID-19 case, and comorbidities [15]. Although hypertension and type 2 diabetes were associated with a higher risk for poor outcomes in COVID-19 patients [16], no relationship was found with positive $\operatorname{lgM} / \mathrm{lgG}$. Educational level, household size, and symptoms were associated with the presence of antibodies $[6,14,15]$. In our study, as expected, previous COVID-19 symptoms were associated with seropositivity (OR 4.06, 95\% Cl 2.99-5.51, $\mathrm{P}<0.001)$, although a higher OR was reported by Garcia-Bateiro et al. (OR 8.8, 95\% Cl 4.41-17.73, $\mathrm{P}<0.0001$ ) [15]. Among the symptoms reported, anosmia showed the strongest association in our analysis. Asymptomatic cases (59.1\%) compared with other countries were higher than the $32.7 \%$, and $52.4 \%$ reported in the general population and health-care workers in Spain, respectively $[5,15]$. As much as approximately $80 \%$ of infections are expected to be asymptomatic or mild [17].

Recent studies indicate some limitations of antibody testing, besides the inherent diagnostic performance. Although antibodies are expected to correlate with infection and disease presentation, a recent Chinese study showed that some infected individuals did not produce neutralizing humoral evidence of SARS-CoV-2 infection. In 10 (5.7\%) out of 175 COVID-19 recovered patients who experienced mild symptoms, neutralizing antibodies against SARS-CoV-2 were unable to cross-react with the SARSCoV-2 virus [18]. Thus, other immune responses, such as $T$ cells and cytokines, may be involved in recovery. Furthermore, Long et al. reported than $40 \%$ of asymptomatic patients became seronegative for IgG in the early convalescent phase [19] suggesting a weaker humoral response that might have implications in the results of serological surveys confounding the true exposure rate.

Our serosurvey has some limitations that may be considered. First, we performed an isolated $\operatorname{lgM} / \operatorname{lgG}$ test, obtaining a cross-sectional seroprevalence. A prospective and longitudinal survey will be highly valuable in following seroconversion and determining household transmission and lockdown effect in the long-term. Second, children were not included in the survey; additional studies will be needed to determine SARS-CoV-2 spread in this group. Finally, due to the study design, these results represent our sampled population's prevalence estimates and do not necessarily reflect the entire state prevalence. Otherwise, as 
strengths for the study, we used an appropriate and powered sample size to provide a reference prevalence value. Also, it seems we surveyed at the right epidemic moment (WHO Phase 3 ). Besides, we used a high-sensitivity chemiluminescent immunoassay, as reported by Muench et al. [20], which has shown a better diagnostic performance than other tests.

In conclusion, this study provides a regional estimation of SARS-CoV-2 dissemination in the densely populated northern region of our country. Six in ten infections were asymptomatic, and despite the significant impact of COVID-19 in Mexico, seroprevalence is still very low and, more importantly, far from herd immunity. Epidemiological surveillance and preventive measures to avoid transmission, such as social distancing and facial masks use, should still be enforced in the population.

\section{Abbreviations}

Anti-SARS-CoV-2: Severe acute respiratory syndrome coronavirus 2 antibodies

BMl: Body mass index

Cl: Confidence interval

COI: Cut-off index

COVID-19: Coronavirus disease 19

IgM: Immunoglubulin type M

IgG: Immunoglobulin type G

PCR: Polymerase chain reaction

OR: Odds ratio

\section{Declarations}

\section{Acknowledgments}

We thank Sergio Lozano-Rodríguez, M.D. for his critical reading and editing of the manuscript.

\section{Authors' contribution}

All named authors met the International Committee of Medical Journal Editors (ICMJE) criteria for authorship. CDS, ASG, and JGGG developed the concept and design. JGGG, CDS, and DSR contribute to the implementation of the study protocol. ASG, RRG, and ACO participated in data collection and statistical analysis. CDS, ASG, RRG, and JGGG contributed to data interpretation, and ASG, CDS, and ACO 
wrote the manuscript with input from all authors. All authors provided critical feedback for intellectual content and approved the final version of the manuscript.

\section{Funding}

This research was supported by the Endocrinology Division, Department of Internal Medicine of the "Dr. Jose Eleuterio Gonzalez" University Hospital, Universidad Autónoma de Nuevo León.

\section{Availability of data and materials}

All data generated or analyzed during this study are included in this published article. The datasets generated are available from the corresponding author on reasonable request.

\section{Ethics approval and consent to participate}

The study was approved by the Institutional Review Board of the School of Medicine and "Dr. Jose E. Gonzalez" University Hospital. (EN20-00025). Written informed consent was obtained from all participants.

\section{Consent for publication}

Not applicable.

\section{Competing interests}

The authors declare that they have no conflicts of interests.

\section{References}

1. COVID-19 Mexico Database. National Epidemiology Center. Mexico Government. https://coronavirus.gob.mx/datos/\#DOView, 2020 (Accessed 31 August 2020).

2. COVID-19 Cases in Nuevo León. Nuevo León Health Department. https://www.nl.gob.mx/publicaciones/casos-de-covid-19-en-nuevo-leon, 2020 (Accessed 31 August 2020).

3. Barrientos-Gutiérrez T, Alpuche-Aranda C, Lazcano-Ponce E, Pérez-Ferrer C, Rivera-Dommarco J. Public health in the first wave: a research agenda for cooperation under Covid-19. Salud Publica Mex 2020. doi: 10.21149/11606. Online ahead of print.

4. Fischer $B$, Knabbe $C$, Vollmer T. SARS-CoV-2 IgG seroprevalence in blood donors located in three different federal states, Germany, March to June 2020. Euro Surveill 2020; 25(58):2001285. doi:10.2807/1560-7917.ES.2020.25.28.2001285.

5. Pollán M, Pérez-Gómez B, Partor-Barriuso R, Oteo J, Hernán MA, Pérez-Olmeda M. Prevalence of SARS-CoV-2 in Spain (ENE-COVID): a nationwide, population-based seroepidemiological study. Lancet 2020; 396(10250):535-44. doi: 10.1016/S0140-6736(20)31483-5. 
6. Stringhini S, Wisniak A, Piumatii G, Azman A, Lauer SA, Baysson H, et al. Seroprevalence of antiSARS-CoV-2 IgG antibodies in Geneva, Switzerland (SEROCoV-POP): a population-based study. Lancet 2020; 396(10247):313-19. doi: 10.1016/S0140-6736(20)31304-0.

7. Bendavid E, Mulaney B, Sood N, Shah S, Ling E, Bromley-Dulfano R, et al. COVID-19 Antibody Seroprevalence in Santa Clara County, California. medRxiv 2020; medRxiv 2020.04.14.20062463; doi: 10.1101/2020.04.14.20062463.

8. Silveira MF, Barros AJD, Horta BL, Pellanda LC, Victora GD, Dellagostin OA, et al. Population-based surveys of antibodies against SARS-CoV-2 in Southern Brazil. Nat Med 2020; 26(8):1196-99. doi: 10.1038/s41591-020-0992-3.

9. Moscola J, Sembajwe G, Jarrett M, Farber B, Chang T, McGinn T, et al. Prevalence of SARS-CoV-2 Antibodies in Health Care Personnel in the New York City Area JAMA. 2020; e2014765. doi:10.1001/jama.2020.14765

10. Xu R, Huang J, Duan C, Liao Q, Shan Z, Wang M, et al. Low prevalence of antibodies against SARSCoV-2 among voluntary blood donors in Guangzhou, China. J Med Virol 2020; 10.1002/jmv.26445. doi:10.1002/jmv.26445

11. Data Nuevo Leon. Nuevo Leon Economy Department. Nuevo Leon Government. http://datos.nl.gob.mx/n-l-poblacion-total-y-por-municipio/, 2020 (Accessed 26 August 2020).

12. Bendix Carstensen, Martyn Plummer, Esa Laara, Michael Hills (2013). Epi: A Package for Statistical Analysis in Epidemiology. R package version 1.1.44. http://CRAN.R-project.org/package=Epi (Accessed 8 August 2020).

13. Public Health Agency Sweden. Första resultaten från pågående undersökning av antikroppar för covid-19-virus. May 20, 2020. https://www.folkhalsomyndigheten.se/nyheter-och-press/ nyhetsarkiv/2020/maj/forsta-resultaten-fran-pagaende-undersokning-av- antikroppar-for-covid-19virus (accessed August 12, 2020).

14. Amorim-Filho L, Szwarcwald CL, Mateos S, Leon ACM, Medronho R, Veloso VG. Seroprevalence of IgG and IgM anti-SARS-CoV-2 among voluntary blood donors in Rio de Janeiro, Brazil. COVID-19 Global literature on coronavirus disease. WHO, https://preprints.scielo.org/index.php/scielo/preprint/view/404/497, 2020 (Accessed 26 August 2020).

15. Garcia-Basteiro AL, Moncunill G, Tortajada M, Vidal M, Guinocart C, Jiménez A, et al. Seroprevalence of antibodies against SARS-CoV-2 among health care workers in a large Spanish reference hospital. Nat Commun 2020; 11(1):3500. doi: 10.1038/s41467-020-17318-x.

16. Barrera FJ, Shekhar S, Wurth R, Moreno-Pena PJ, Ponce OJ, Hajdenberg M, et al. Prevalence of Diabetes and Hypertension and their Associated Risks for Poor Outcomes in Covid-19 Patients. Journal of the Endocrine Society 2020; bvaa102. doi: https://doi.org/10.1210/jendso/bvaa102

17. Eckerle I, Meyer B. SARS-CoV-2 seroprevalence in COVID-19 hotspots. Lancet 2020; 396(10250): 514515. 
18. Wu F, Wang A, Liu M, Wang Q, Chen J, Xia S, et al. Neutralizing antibody responses to SARS-CoV-2 in a COVID-19 recovered patient cohort and their implications. Medrxiv 2020; medRxiv 2020.03.30.20047365; doi: 10.1101/2020.03.30.20047365.

19. Long QX, Tang XJ, Shi QL, Li Q, Deng HJ, Yuan J, et al. Clinical and immunological assessment of asymptomatic SARS-CoV-2 infections. Nat Med 2020; 26(8):1200-04. doi: 10.1038/s41591-0200965-6.

20. Muench P, Jochum S, Wenderoth V, Ofenloch-Haehnle B, Hombach M, Strobl A, et al. Development and Validation of the Elecsys Anti-SARS-CoV-2 Immunoassay as a Highly Specific Tool for Determining Past Exposure to SARS-CoV-2. J Clin Microbiol 2020; JCM.01694-20. doi: 10.1128/JCM.01694-20. Online ahead of print.

\section{Tables}


Table 1. Demographic and clinical characteristics of the population.

\begin{tabular}{|c|c|c|c|c|}
\hline & $\begin{array}{l}\text { Total sample } \\
(\mathrm{n}=3,268)\end{array}$ & $\begin{array}{l}\text { Negative IgM/IgG } \\
(\mathrm{n}=3,075)\end{array}$ & $\begin{array}{l}\text { Positive } \operatorname{IgM} / \operatorname{IgG} \\
(\mathrm{n}=193)\end{array}$ & $P$ \\
\hline Males, n (\%) & $2008(61.4)$ & $1891(61.5)$ & $117(60.6)$ & 0.82 \\
\hline Age, yrs & & & & 0.29 \\
\hline $18-34, \mathrm{n}(\%)$ & $1127(34.5)$ & $1059(34.5)$ & $68(35.2)$ & \\
\hline $35-49, \mathrm{n}(\%)$ & $1328(40.6)$ & $1242(40.4)$ & $86(44.6)$ & \\
\hline $50-65, \mathrm{n}(\%)$ & $765(23.4)$ & $730(23.7)$ & $35(18.1)$ & \\
\hline$>65, \mathrm{n}(\%)$ & $48(1.5)$ & $44(1.4)$ & $4(2.1)$ & \\
\hline Weight $^{\mathrm{a}}, \mathrm{kg}$ & $80.0(69-90)$ & $80.0(69-90)$ & $82(72-92)$ & 0.15 \\
\hline Height $^{\mathrm{a}}, \mathrm{m}$ & $1.67(1.6-1.7)$ & $1.67(1.6-1.7)$ & $1.67(1.6-1.7)$ & 0.77 \\
\hline $\mathrm{BMI}^{\mathrm{a}}, \mathrm{kg} / \mathrm{m}^{2}$ & $28.41(25.3-32)$ & $28.4(25.2-32)$ & $29.0(25.6-32.6)$ & 0.53 \\
\hline BMI categories & & & & 0.08 \\
\hline Underweight, n (\%) & $17(0.5)$ & $17(0.6)$ & 0 & \\
\hline Normal, n (\%) & $721(22.1)$ & $685(22.3)$ & $36(18.7)$ & \\
\hline Overweight, n (\%) & $1289(39.4)$ & 1209 (39.3) & $80(41.5)$ & \\
\hline Obesity I-III, n (\%) & $1241(38)$ & $1164(37.8)$ & $77(39.8)$ & \\
\hline \multicolumn{5}{|l|}{ Comorbidities } \\
\hline Hypertension, n (\%) & $287(8.8)$ & $269(8.7)$ & $18(9.3)$ & 0.79 \\
\hline Diabetes type 2, n (\%) & $287(8.8)$ & $273(8.9)$ & $14(7.3)$ & 0.51 \\
\hline Obesity, n (\%) & $1241(38)$ & $1164(37.8)$ & $77(39.8)$ & 0.59 \\
\hline City & & & & 0.08 \\
\hline Guadalupe, n (\%) & $1970(60.3)$ & $1846(60.0)$ & $124(64.2)$ & \\
\hline Monterrey, n (\%) & $495(15.1)$ & 257 (8.4) & $17(8.8)$ & \\
\hline Juárez, n (\%) & $274(8.4)$ & $465(15.1)$ & $30(15.5)$ & \\
\hline Other, n (\%) & $530(16.2)$ & 507 (16.5) & $22(11.5)$ & \\
\hline Occupation & & & & 0.001 \\
\hline $\begin{array}{l}\text { Police, firefighters and } \\
\text { public safety, n (\%) }\end{array}$ & $1051(32.2)$ & 982 (31.9) & 69 (35.7) & \\
\hline
\end{tabular}




\begin{tabular}{llll} 
Office/Management, n (\%) & $696(21.2)$ & $660(21.5)$ & $36(18.7)$ \\
\hline Maintainance/Janitors, n (\%) & $608(18.7)$ & $583(18.9)$ & $25(12.9)$ \\
\hline Healt-care workers, n (\%) & $163(5)$ & $155(5)$ & $8(4.1)$ \\
\hline Other, n (\%) & $750(22.9)$ & $695(22.7)$ & $55(28.6)$
\end{tabular}

a Median (IQR). IgG: Type G immunoglobulin; IgM: Type M immunoglobulin.

Table 2. Unadjusted and adjusted seroprevalence estimates.

\begin{tabular}{|c|c|c|}
\hline Approach & Estimates (\%) & $95 \% \mathrm{CI}$ \\
\hline Raw & 5.9 & $5.1-6.8$ \\
\hline Adjusted for test performance ${ }^{a}$ & 5.7 & $4.9-6.6$ \\
\hline
\end{tabular}


Table 3. COVID-19 symptoms during the previous four weeks at the time of the serosurvey.

\begin{tabular}{llll}
\hline & $\begin{array}{l}\text { Seronegative IgM/IgG } \\
(\mathrm{n}=3,075)\end{array}$ & \multicolumn{2}{l}{ Seropositive IgM/IgG } \\
& $2627(\mathrm{n}=193)$ & $P$ \\
\hline Asymptomatic, n (\%) & $448(14.6)$ & $114(59.1)$ & $<0.001$ \\
\hline Symptomatic, n (\%) & & $49(40.9)$ & $<0.001$ \\
\hline Self-reported symptoms & $119(3.9)$ & $47(24.4)$ & $<0.001$ \\
\hline Cough, n (\%) & $202(6.6)$ & $15(7.8)$ & $<0.001$ \\
\hline Sore throat, n (\%) & $85(2.8)$ & $32(16.6)$ & 0.001 \\
\hline Nasal discharge, n (\%) & $173(5.6)$ & $40(20.7)$ & $<0.001$ \\
\hline Headache, n (\%) & $63(2.0)$ & $31(16.1)$ & $<0.001$ \\
\hline Anosmia, n (\%) & $98(3.2)$ & $23(11.9)$ & $<0.001$ \\
\hline Muscle/body aches, n (\%) & $92(3.0)$ & $29(15.0)$ & $<0.001$ \\
\hline Diarrhea, n (\%) & $62(2.0)$ & $21(10.9)$ & $<0.001$ \\
\hline Fever, n (\%) & $40(1.3)$ & $39(20.2)$ & 0.013 \\
\hline Shortness of breath, n (\%) & $416(13.5)$ &
\end{tabular}

COVID-19: Coronavirus disease 2019; IgG: Type G immunoglobulin; IgM: Type M immunoglobulin. 
Table 4. Univariate and multivariate analysis of factors associated with positive anti-SARS-CoV-2 antibodies.

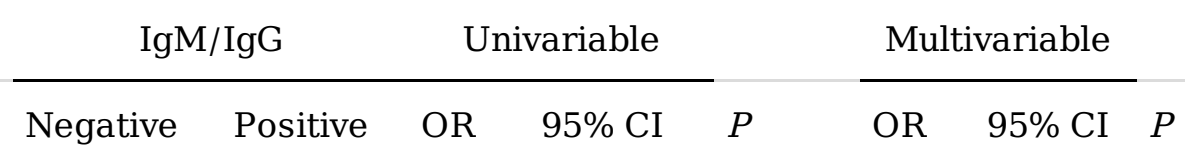

\section{Gender}

$1891 \quad 117$

Males, n (\%)

(61.5)

(60.6)

0.96

$0.72-1.30 \quad 0.82$

City of residence

$1846 \quad 124$

Guadalupe , n (\%)

(60.0)

$(64.2)$

$1.20 \quad 0.89-1.62 \quad 0.26$

\section{Occupation}

Police, firefighters \& public safety, $\mathrm{n}$

$982(31.9) \quad 69(35.8) \quad 1.19 \quad 0.88-1.61 \quad 0.27$

Office/Management, n (\%)

660 (21.5) 36 (18.7) $\quad 0.84 \quad 0.58-1.21 \quad 0.41$

$0.46-$

Cleaning/Mantainance, n (\%)

\begin{tabular}{llllllll}
$583(18.9)$ & $25(12.9)$ & 0.64 & $0.41-0.98$ & 0.04 & $0.71^{\mathrm{b}}$ & 1.10 & 0.13 \\
\hline $155(5.0)$ & $8(4.1)$ & 0.82 & $0.40-1.68$ & 0.73 & & & \\
$695(22.7)$ & $55(28.6)$ & 1.37 & $0.99-0.89$ & 0.06 & & &
\end{tabular}

\section{Comorbidities}

Hypertension, n (\%)

269 (8.7) $\quad 18(9.3) \quad 1.07 \quad 0.65-1.77 \quad 0.79$

Diabetes, n (\%)

$273(8.9) \quad 14(7.3) \quad 0.80 \quad 0.46-1.40 \quad 0.51$

1164

Obesity, n (\%)

(37.9)

77 (39.9) $\quad 1.09 \quad 0.81-1.47 \quad 0.59$

1481

100

Any comorbiditie ${ }^{\mathrm{a}}$, n (\%)

(48.2)

(51.8)

$1.16 \quad 0.87-1.55 \quad 0.34$

\section{COVID-19 symptoms}

$2627 \quad 114$

Asymptomatic, n (\%)

(85.4)

(59.1)

0.25

$0.18-0.33<0.001$

2.86- 


\begin{tabular}{|c|c|c|c|c|c|c|c|c|}
\hline Cough, n (\%) & 119 (3.9) & $47(24.4)$ & 7.98 & $5.49-$ & $<0.001$ & $4.17^{\mathrm{C}}$ & $2.50-$ & $<0.001$ \\
\hline & & & & 11.65 & & & 6.93 & \\
\hline Sore throat, n (\%) & $202(6.6)$ & $33(17.1)$ & 2.93 & $1.96-4.38$ & $<0.001$ & & & \\
\hline Nasal discharge, n (\%) & $85(2.8)$ & $15(7.8)$ & 2.97 & $1.68-5.24$ & 0.001 & & & \\
\hline Shortness of breath, n (\%) & $40(1.3)$ & $21(10.9)$ & 9.26 & $5.34-6.06$ & $<0.001$ & & & \\
\hline \multirow[t]{2}{*}{ Headache, n (\%) } & $173(5.6)$ & $32(16.6)$ & 3.33 & $2.21-5.02$ & $<0.001$ & & & \\
\hline & & & & $8.22-$ & & & $3.41-$ & \\
\hline Anosmia, n (\%) & $63(2.0)$ & $40(20.7)$ & 12.62 & 19.37 & $<0.001$ & $5.75^{\mathrm{c}}$ & 9.71 & $<0.001$ \\
\hline Diarrhea, n (\%) & $92(3.0)$ & $23(11.9)$ & 4.39 & $2.71-7.12$ & $<0.001$ & & & \\
\hline \multirow[t]{2}{*}{ Muscle pain, n (\%) } & $98(3.2)$ & $31(16.1)$ & 5.81 & $3.77-8.97$ & $<0.001$ & & & \\
\hline & & & & $5.38-$ & & & $1.30-$ & \\
\hline Fever, n (\%) & $62(2.0)$ & $29(15.0)$ & 8.59 & 13.72 & $<0.001$ & $2.44^{\mathrm{c}}$ & 4.58 & 0.006 \\
\hline Contact with confirmed case, $n$ (\%) & $416(13.5)$ & $39(20.2)$ & 1.62 & $1.12-2.34$ & 0.013 & & & \\
\hline
\end{tabular}

a Other cardiovascular, allergic, endocrine, and neurological diseases. ${ }^{\mathrm{b}}$ Adjusted for cleaning/maintenance,

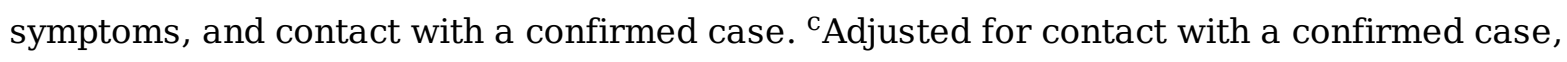
cleaning/maintenance, sore throat, and headache. OR: Odds ratio; CI: Confidence interval.

\section{Figures}




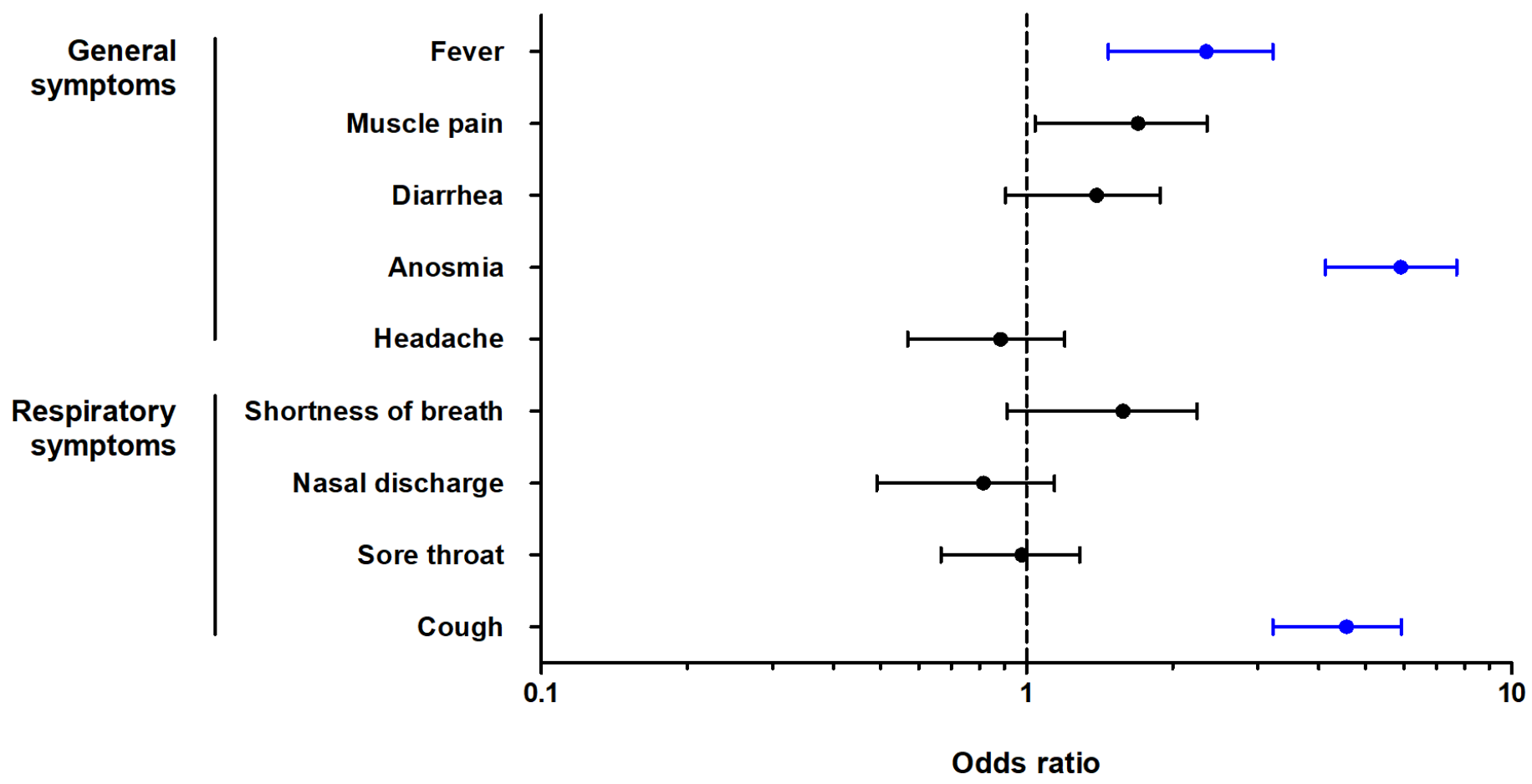

Figure 1

Odds ratios for symptoms associated with positive $\mathrm{IgM} / \mathrm{lg}$ against SARS-CoV-2 in the multivariate model. In blue, statistically significant symptoms: anosmia $(5.4,95 \% \mathrm{Cl} 3.1-9.2, \mathrm{P}<0.001)$, cough $(4.2,95 \%$ Cl 2.4-7.1, $\mathrm{P}<0.001)$, and fever $(2.0,95 \% \mathrm{Cl} 1.02-3.9, \mathrm{P}=0.04)$. 